\title{
INVESTIGATING INFECTIOUS AND ZOONOTIC DISEASES OF STREET DOGS IN THE RESIDENTIAL AREA OF BANGLADESH AGRICULTURAL UNIVERSITY
}

\author{
T. K. Kasfi ${ }^{1}$, S. S. Labony ${ }^{2}$, M. G. A. Chowdhury ${ }^{1}$, U. K. Rima ${ }^{1}$, M. Z. Hossain ${ }^{1}$, S. J. H. Chowdhury ${ }^{3}$, M. \\ M. Hossain ${ }^{1}$ and M. A. H. N. A. Khan ${ }^{1 *}$ \\ ${ }^{1}$ Department of Pathology, Faculty of Veterinary Science, Bangladesh Agricultural University \\ Mymensingh-2202, Bangladesh \\ ${ }^{2}$ Department of Parasitology, Faculty of Veterinary Science, Bangladesh Agricultural University \\ Mymensingh-2202, Bangladesh \\ ${ }^{3}$ Bangladesh Agricultural Research Councill (BARC), Farmgate, Dhaka, Bangladesh
}

\begin{abstract}
Dogs are common carnivor and scavenger at Bangladesh Agricultural University (BAU) campus. Dogs may carry many infectious and zoonotic diseases and could play a role in transmitting those diseases in other carnivors and human as well. At day time cats, dogs and golden jackals are found to eat in a same dustbin at BAU campus. So it is possible to share diseases of each other and there are possibilities of crossing species barrier. This study was, therefore, aimed at specific investigation of the occurrence of leishmaniasis, canine distemper (CD), infectious canine hepatitis (ICH) and avian influenza (AI) of dogs at BAU campus. This study was carried out during the period from January to June/ 2012. A total of 10 apparently healthy dogs were euthanatized and postmortem examination were carried out. Impression smears were prepared from spleen, liver, bone marrow and stained with Giemsa's stain. Histopathological studies were conducted using routine procedures. For molecular characterization, polymerase chain reaction (PCR) and Reverse Transcriptase polymerase chain reaction (RT-PCR) were adopted for the detection of genomic fragment of visceral leishmaniasis (VL), canine distemper (CD), infectious canine hepatitis (ICH) and avian influenza (AI, viral matrix protein gene). Results of this study showed the presence of leishmania organism in the impression smears of eight dogs. Using PCR amplification technique, Leishmania donovani specific genomic DNA (145bp) was detected in two dogs . PCR amplification of genomic DNA of ICH ( $411 \mathrm{bp}$ ) and RT-PCR amplification of genomic RNA of CD (287bp) and matrix protein gene of AI (245bp) were not detected in any of the dogs of BAU campus. Future work is needed to explore the presence of snad flies (vector of VL) in the investigating areas and establish role of street dogs of BAU campus towards disseminating leishmaniasis in other animals and human beings.
\end{abstract}

Key words: Street dogs, visceral leishmaniasis, Canine diseases, Avian influenza, giemsa's staining, PCR

\section{INTRODUCTION}

Street dogs are important domestic carnivor and scavanger of the environment of BAU campus. There are huge numbers of street dogs, golden jackals and cats living around BAU campus and often found to play and eat in same tale. Dogs are the usual connectors between the people, animals and nature. Dogs act as reservoirs in the transmission of numerous infectious, emerging and zoonotic diseases, creating risk on to the health of both wildlife and human as well. Among the diseases, leishmaniasis or kala-azar is becoming a common threat for both human and animal welfares. Human and canine visceral leishmaniasis (CVL), a typical rural disease associated with precarious conditions of life (Bevilacwua et al., 2001). It is a chronic parasitic infection that infects approximately 400,000 individuals annually, with a predilection towards early childhood (Grech et al., 2000). The spatial evolution of the epidemic showed that the canine cases had preceded the human cases confirming the importance of dogs as reservoir in urban areas (Bevilacwua et al., 2001).

Canine distemper (CD) on the other hand is a serious, often fatal viral disease in dogs and many other carnivores (Appel, 1987; Yousuf et al., 2014). CD is a highly contagious disease of young dogs, distributed worldwide and infect particularly 3 to 6 months age group with high morbidity and mortality. It is manifested by a biphasic fever, leukopenia, gastroenteritis, respiratory catarrh, frequently pneumonia and neurological complications (Aiello and Mays, 1998). CD was detected in golden jackals of char areas of Brahmaputra river next to Bangladesh Agricultural University (Yousuf, 2008) campus.

*Corresponding e-mail address: hadikhan1968@gmail.com 


\section{T. K. Kasfi and others}

Infectious canine hepatitis (ICH) is an adenoviral disease of young Canidae and Uridae, is characterized clinically by in apparent to rapidly fatal disease (Greene et al., 1990). Canine adenovirus-I (CAV-1) is both endotheliotropic and hepatotropic. In addition to acute hepatocellular necrosis, acute severe hemorrhages are seen on serosal surfaces, within lymphnodes and the liver, and rarely in the brain (Greene, 1990; Kelly et al., 1993).

The H5N1 influenza viruses have been isolated from several mammalian hosts (Keawcharoen et al., 2004; Amonsin et al., 2006; Zhu et al., 2008). Pigs, for example, are regarded as a natural influenza virus host that could be infected by an H5N1 influenza virus in the field or an experimental setting (Lipatov et al., 2008; Zhu et $a l ., 2008$ ) and could lead the generation of an H5N1 pandemic strain. Cats and dogs, which come into close contact with humans, may also play a role in the interspecies transmission of influenza viruses. Songserm et al. (2006) reported natural infection of dog with a natural outbreak of H5N1 influenza virus and recorded systemic replication of the virus in $\mathrm{dog}$. This study was aimed to adopt protocols for the detection of selected genomic fragments of $\mathrm{VL}, \mathrm{ICH}, \mathrm{CD}$ and $\mathrm{AI}$ matrix protein genes and designed strategies to prevent its future dessimination.

\section{MATERIALS AND METHODS}

The investigation was carried out in the Department of Pathology, Faculty of Veterinary Science, Bangladesh Agricultural University (BAU), Mymensingh, Bangladesh. A total of 10 apparently healthy dogs were caught by the dog catchers of district public health corporation, Mymensingh, euthanatized by intravenous injection of saturated solution of magnesium sulfate and brought for investigation to the Department of Pathology, BAU during the period from January-June, 2012. Systemic dissection and investigation was carried out and liver, lymph node, kidney, spleen, heart, lungs, bone marrow, intestine and skin were collected.

\section{Preparation of impression smears}

A thin smear of blood and impression smears from the cut surface of liver, lungs, spleen and bone marrow were made on to clean slides and stained with Giemsa's stain (Luna, 1968). A low (10x) and high power (40x and 100x) microscopic observation were carried out to investigate the promastigote and amastigote stages of leishmanial protozoa in tissue spaces and in macrophages of various organs. Investigation onto the impression smears of liver was also carried out at 100x objective to find out hepatic intranuclear inclusion bodies of ICH and intranuclear and intracytoplasomic inclusion bodies in the cell smears prepared from lungs suggestive for CD.

\section{Histopathological investigation of tissues}

During necropsy liver, lungs, spleen, intestine and skeletal muscles from all dogs were collected and fixed in $10 \%$ buffered neutral formalin for histopathological studies. Formalin fixed tissue samples were trimmed, processed, sectioned and stained with Hematoxylin and Eosin staining (Luna, 1968). A low (10x objective) and high power (40x, 100x objectives) microscopic examination were carried out to observe the changes related to specific infections.

\section{Detection of VL and ICH by PCR \\ DNA extraction}

Wizard genomic DNA extraction Kit (Promega Inc, USA) was used to extract genomic DNA for the detection of genomic fragments of Leishmania and $\mathrm{ICH}$. Portion of liver and spleen of street dogs were also collected and extracted genomic DNA using manufacturer instruction (Khan et al., 2012). Spectophotometry $\left(\mathrm{A}_{260}\right.$ and $\left.\mathrm{A}_{280}\right)$ and agarose gel ectrophoresis were done for confirmation of the purity and concentration of DNA. Primer sets from published literature (Table 1) were used to identify causal agent of VL ( L. donovani) and viruses of ICH.

\section{PCR detection of VL and ICH}

PCR reactions were adopted for the detection of genomic fragments of L. donovani (Khan et al., 2012) and ICH viruses. PCR was carried out in a final reaction volume of $25 \mu l$ in the thin walled PCR tubes. The Promega Inc PCR Master Mix Kit was used to amplify genomic DNA in a programmable thermocycler. The thermal profile used was an initial denaturation for four minutes at $94^{\circ} \mathrm{C}$ followed by 45 cycles of DNA amplification reaction in a Master Cycler (Master Cycler Gradient, Eppendorf, Germany). The condition of PCR amplifications 
Investigating infectious and zoonotic diseases of street dogs

were denaturation for $60 \mathrm{sec}$ at $94^{\circ} \mathrm{C}$, annealing for $90 \mathrm{sec}$ at $61^{\circ} \mathrm{C}$ and extension for $60 \mathrm{sec}$ at $72^{\circ} \mathrm{C}$ followed by a final extension for $10 \mathrm{~min}$ at $72^{\circ} \mathrm{C}$. The PCR reactions were held at $4{ }^{\circ} \mathrm{C}$ and finally the reaction was terminated by adding $3 \mu 150 \mathrm{mM}$ EDTA. The PCR products were analyzed by electrophoresis in $1.5 \%$ agarose gel, stained with ethidium bromide and examined under UV light using an image documentation system (Cell Biosciences, Alphalmager HP, USA).

Table 1. Primers and their sequences used to detetct genomic fragments of VL, ICH, CD and AI from the internal organs of street dogs

\begin{tabular}{llll}
\hline Primers name & Sequences (5'-3') of primer & Amplicon size/ diseases & References \\
\hline LDF $_{1}$ & CTTTTCTGGTCCCGCGGTAGG & $145 \mathrm{bp} / \mathrm{VL}$ & Gomes et al., 2006 \\
$\mathrm{LDR}_{1}$ & CCACCTGGCCTATTTTAACCA & & Chouinard et al., 1998 \\
$\mathrm{ICHF}$ & CACTCGAGATGGCCATCTTAATAT & $411 \mathrm{bp} / \mathrm{ICH}$ & \\
$\mathrm{ICHR}$ & TCCTGCAGTTTAGAGCGGACCCTG & & Frisk et al., 1999 \\
$\mathrm{CDF}$ & ACAGGATTGCTGAGGACCTAT & \multirow{2}{*}{$287 \mathrm{bp} / \mathrm{CD}$} & \\
$\mathrm{CDR}$ & CAAGATAACCATGTACGGTGC & & Fouchier et al., 2000 \\
MPAIF & CTTCTAACCGAGGTCGAAACG & $245 \mathrm{bp} / \mathrm{AI}$ & \\
MPAIR & AGGGCATTTTGGACAAAKCGTCTA & & \\
\hline
\end{tabular}

\section{RT-PCR detection of CD and AI viruses \\ RNA extraction protocol}

RNA from the host tissues including viral RNA was extracted from liver and spleen of street dogs using commercially available RNA extraction Kit (Promega INC, USA) and used the protocol as described by the manufacturer. The purity and concentration of RNA was determined by using spectophotometry (A $\left.{ }_{260} / \mathrm{A}_{280}\right)$ and agar gel electrophoresis.

\section{RT-PCR detection of CD and AI viruses}

One step RT-PCR was carried out with a total of $25 \mu$ of reaction volume. The $2 \mathrm{x}$ master mix was dispensed to each PCR tubes containing 20pmol primers of each and 100-150ng/ 5 $\mu$ l extracted RNA. The RT-PCR protocols were adopted and carried out in a Master Cycler (Master Cycler Gradient, Eppendorf, Germany). The thermal profile used for CD Viruses comprised a reverse transcription for $30 \mathrm{~min}$ at $50^{\circ} \mathrm{C}\left(42^{\circ} \mathrm{C}\right.$ for $\left.\mathrm{AI}\right)$. The subsequent PCR were carried out with an initial denaturation for $4 \mathrm{~min}$ at $94^{\circ} \mathrm{C}$ followed by 40 cycles of amplification reaction. The condition of PCR amplifications were denaturation for $60 \mathrm{sec}$ at $94^{\circ} \mathrm{C}$, primer annealing for $2 \mathrm{~min}$ at $59.5^{\circ} \mathrm{C}\left(60 \mathrm{sec}\right.$ at $45^{\circ} \mathrm{C}$ for $\left.\mathrm{AI}\right)$ and extension for $3 \mathrm{~min}$ at $72^{\circ} \mathrm{C}$ followed by a final extension for $10 \mathrm{~min}$ at $72^{\circ} \mathrm{C}$. The RT-PCR reactions were held at $10^{\circ} \mathrm{C}$ and the reaction was terminated by adding $3 \mu 150 \mathrm{mM}$ EDTA. The RTPCR products were analyzed by electrophoresed in $1.5 \%$ agarose gel, stained with ethidium bromide and examined under UV light using an image documentation system (Cell Biosciences, Alphalmager HP, USA).

\section{RESULTS AND DISCUSSION}

Dogs are the carrier of many infectioous and zonotic diseases, hence investigation were carried out on to randomly selected $10 \mathrm{dogs}$ of BAU campus to identify the presence of Leishmania donovani, Canine distemper, Infectious canine hepatitis and Avian influenza (matrix protein) organisms. Necropsy, staining of impression smear with Giemsa's, histopathological examination, PCR and RT-PCR protocols were adopted. Physical examination of the dogs revealed rough hair coats and alopecia (Fig. 1a). Spleens were enlarged and lungs were irregularly consolidated and blackened $(\mathrm{N}=02)$. There was splenomegaly and enlarged liver in two dogs and it could be due to subclinical form of leishmanisis (Petersen, 2009).

Leishmanial promastigote like organisms were seen in the impression smears prepared from spleen, liver and bone marrow (Fig. 2) stained with Giemsa's stain. Protozoa similar to promastigotes phases of Leishmania in the organ smears was seen and indicated infection with Leishmania spp (Al-Shamahy (2003). Small oval shape parasites with dark nucleus and a small kinetoplast were seen in the impression smear of liver and spleen (Noli, 1999). Out of $10 \mathrm{dogs}$ examined, eight showed the presence of promastigote stage of leishmania in liver, spleen and bone marrow. 


\section{T. K. Kasfi and others}

About $83.4 \%$ infectivity of dogs with the promastigotes of Leishmania spp in either liver or spleen was reported with reactive cellular infiltration (Al-Shanawi, 1975). However, using impression smear staining species of Leishmania involved could not be identified.

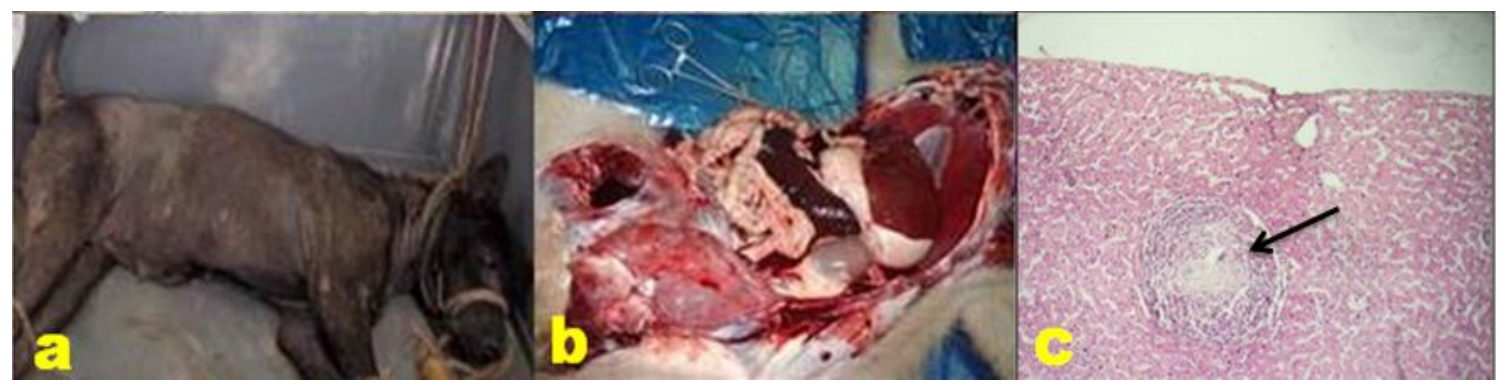

Fig. 1. Investigating street dogs (a) for the detection of diseases. At necropsy dominant lesion was only seen in the skin and internal organs and were apparently healhty (b). Following histopathology, nodular lesion in liver (c, arrow, 10x) characteristics of Visceral leishmaniasis was seen in a dog.

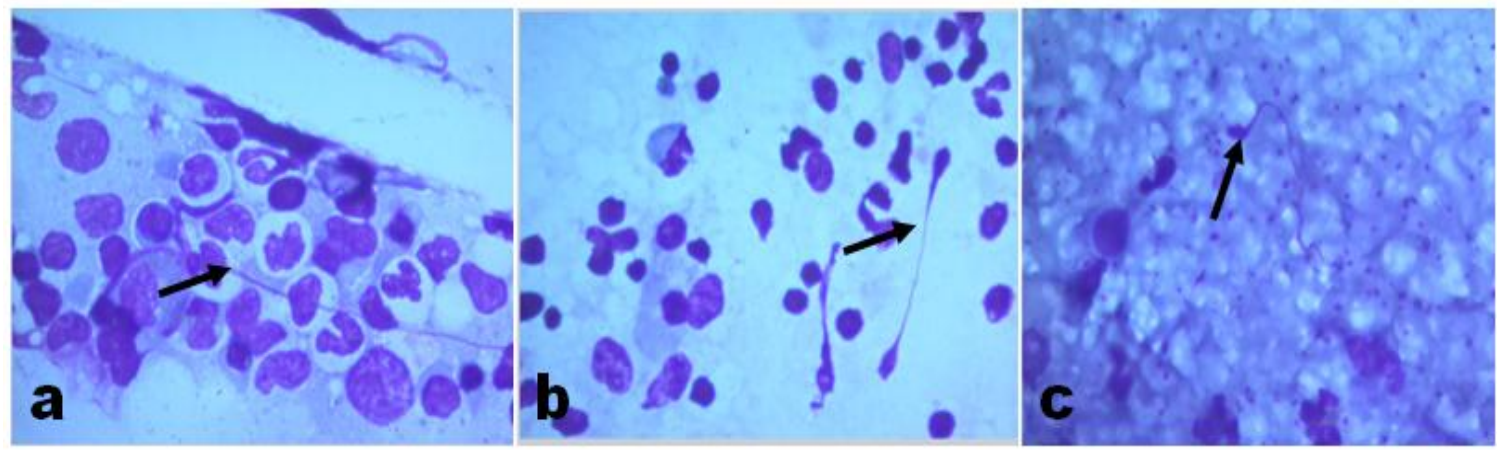

Fig. 2. Impression smears prepared from bone marrow (a), spleen (b) and liver (c) stained with Giemsa's stain . Promastigote (black arrow, 100X) phases of the Leishmania protozoa was seen in the smears prepared from bone marrow, spleen and liver.

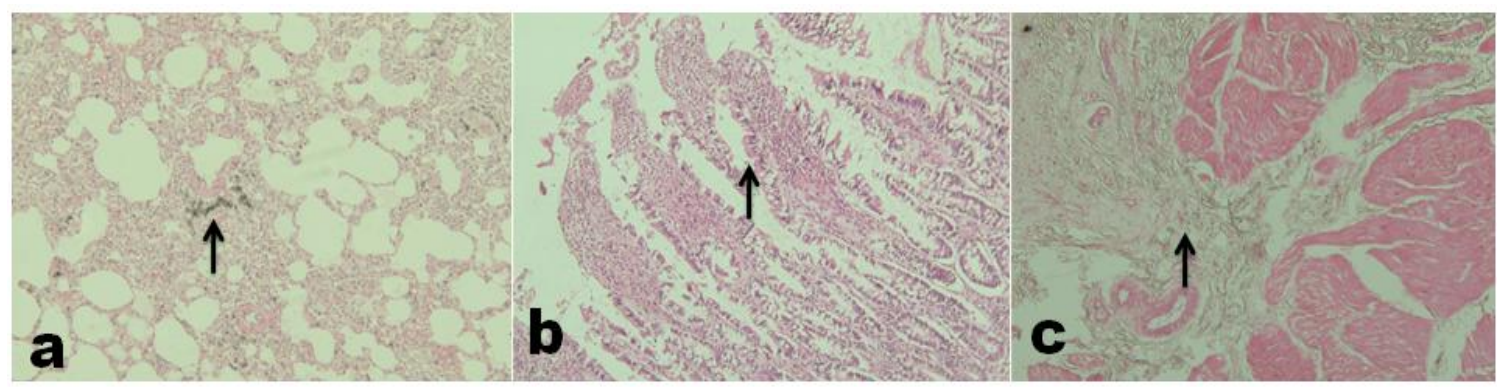

Fig. 3. Section of lungs, intestine and skeletal muscle stained with H\&E. Deposition of black coloured carbon particle (Carbon - Anthracosis) in the alveolar septal wall and macrophages (black arrow, 10X) of lungs (a) was seen . There was catarrhal enteritis and sloughing of mucosal epithelium (black arrow, 10X) in intestinal mucosa (b). Focal necrosis in the skeletal muscle (c) and deposition of reticular and elastic fiber in the space between necrotic muscle bundles (black arrow, 10X) were seen. 
In histopathological examination, leishmanial amastigote and promastigotes were found only in the spleen. The presence of large number of promastigote in spleen without tissue reaction and lacking of inflammation incriminated dogs as asymptomatic carrier of VL. Granuloma formation and presence of necrosis or proliferation of connective tissues and giant cells in chronically infected liver can be seen (Tryphonas et al., 1977). Early lesions with high parasitic load can show granuloma at the edge of lesions and deeper sections of the biopsy (Mansur et al., 1970). Nonspecifically, there was deposition of black colored carbon particle (anthracosis) in the alveolar epithelium and macrophages of lungs (Fig. 3a) and these could be due to living ecology of dogs close proximity of rice mills or other carbon sources. Catarrhal enteritis and sloughing of mucosal epithelium of intestine was seen in three cases (Fig. 3b). In a case there was necrosis of skeletal muscle and e xcessive deposition of reticular and elastic fiber in the space between necrotic muscle bundles was seen (Fig. 3c). The reason of necrosis in skeletal muscle could not be explained but the necrosed area was replaced by reticular fiber. Histopathological examination of liver section did not reveal major alteration . Intracytroplasmic inclusion body in liver and intranuclear and intracytoplasomic inclusion body in lungs specific to ICH and CD respectively were not seen. So the presence of ICH and CD in the liver of dogs was not documented by histological technique.

L PC NC $\begin{array}{llllllllllll}1 & 2 & 3 & 4 & 5 & \text { L } & \text { NC } & 1 & 2 & 3 & 4 & 5\end{array}$

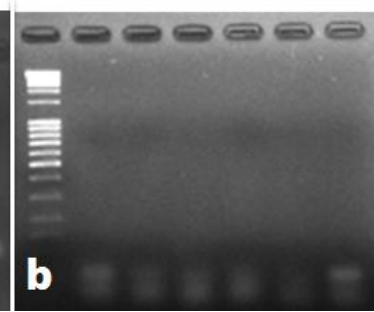

L NC $\quad \begin{array}{lllll}1 & 2 & 3 & 4 & 5\end{array}$

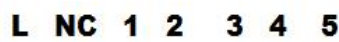

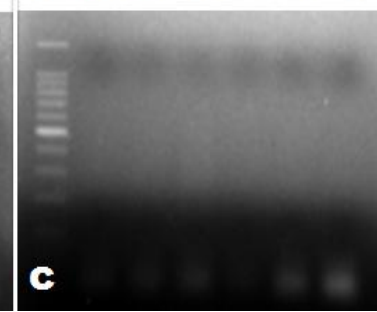

Fig. 4. PCR detection of visceral leishmaniasis (a, 145bp) and infectious canine hepatitis (b, $411 \mathrm{bp})$ from the genomic DNA of liver of dogs. RT-PCR detection of canine distemper (c, 287bp) from the liver and matrix protein gene of avian influenza (d, 245bp) from lungs of street dogs. Lane L is for 100bp ladder, PC is for positive control, NC is for negative control and lane 1 to 5 are for genomic DNA or RNA used in PCR or RT-PCR amplification reaction. Out of ten dogs examined visceral leishmania specific amplicon (145bp, a) was generated in two cases.

It is often difficult to diagnose species of Leishmania involved in impression smear staining due to lack of technology of morphologic differentiation of the parasites and often presences of non pathogenic form of Leishmania as well. PCR is a highly sensitive and specific technique used to detect Canine leishmaniasis (Torres, 2007). This study used species specific primers in PCR against L. donovani and successfully amplified 145bp products from the template DNA obtained from the liver of two dogs $(2 / 10)$ indicated the presences of $L$. donovani (Fig. 4a). The serological and molecular tests often used to detect leishmaniasis in canids. Cortes et al. (2004) conducted a study on 20 dogs and four dogs were positive to VL using serology and 16 using PCR suggesting the higher sensitivity of the PCR test protocol. In this study direct smear staining revealed the presence of leishmanial pro-mastigote or a-mastigote stages of protozoa in eight cases but using PCR only two dogs were positive to VL. The increase reactivity of the dogs in impression smears technology could be due to lack of specific staining reactivity and could also be due to the presence of non-pathogenic leishmania like protozoa in smears.

Characteristics lesions selective for ICH in in internal organs d uring necropsy and histopathological investigation was not seen, PCR assay was, therefore, used for the detection of fragments of ICH. The PCR assay was done with the genomic DNA from the liver of $10 \mathrm{dogs}$ using published primer sequences (Chouinard et al., 1998) but did not amplify desired (411bp) band in gel documentation (Fig. 4b). It was assumed that dogs of BAU campus were not infected with ICH virus. RT-PCR was, therefore, used to detect genomic content of CD virus in clinical specimens of street dogs but did not develop desire (287bp) amplicon (Fig. 4c). A definitive diagnosis of canine distemper virus by isolation on canine cells is time consuming; taking several days to weeks, notably when applied to clinical specimens (Frisk et al., 1999; Kim et al., 2001and Shin et al., 2004). RT- PCR assays for the detection of CD virus offer substantial improvements in virus detection and thus may render easier 


\section{T. K. Kasfi and others}

the control of CD in dogs (Frisk et al., 1999; Von Messling et al., 1999; Rezk, 2000; Mizak et al., 2002; Shin et al., 2004 and Saito et al., 2006, Yousuf et al., 2014). Wild carnivores are at high risk of catching highly pathogenic avian influenza (HPAI) virus (H5N1) due to eating habit of infected dead birds either domesticated or wild. AI virus specific RT-PCR was adopted targetting MP gene but did not amplify desire amplicon (Fig.4d). AI viral infection was not detected in any of the 10 dogs in this study.

$\mathrm{T} \quad$ his study provides evidence that Leishmania like protozoa was present in the internal organs of eight street dogs of BAU campus. Results of PCR (145bp amplicon) showed the presence of L. donovani in the liver of two dogs. Canine distemper, infectious canine hepatitis and avian influenza viral genomes were not detected in any of the dogs of BAU campus. It needs to test large number of sample using wider primers pair to confirm the presence of other species of Leishmania and detection of vector available at BAU campus.

\section{ACKNOWLEDGEMENT}

Thanks are due to SPGR, PIU-BARC, NATP Phase-1 (April 2010 to June 2014) for funding the research.

\section{REFERENCES}

1. Aiello SE and Mays A (1998). Canine Distemper. In: The Merck Veterinary Manual. $8^{\text {th }}$ edn. Merck \& Co., INC, Whitehouse station, N.J., U.S.A.: 548-550.

2. Al Shanawi $\mathrm{F}$ (1975). Comparison of the course of laboratory infection in Iraqi strain of Leishmania donovani. $M S c$ Thesis, College of Science, University of Baghdad.

3. Al-Shamahy H (2003). Prevalence of canine and human leishmaniasis in Yemen. Operational research in tropical diseases final report summaries 1992-2000 results portfolio of the small grants scheme, 45: 22-23 (www.docstoc.com/docs/92385457).

4. Amonsin A, Payungporn S, Theamboonlers A, Thanawongnuwech R, Suradhat S, Pariyothorn N, Tantilertcharoen R, Damrongwantanapokin S, Buranathai C, Chaisingh A, Songserm T and Poovorawan Y (2006). Genetic characterization of H5N1 influenza A viruses isolated from zoo tigers in Thailand. Virology 344: 480-491.

5. Appel MJG and Horzinek MCM (1987). Elsevier Science Publishers BV. Canine distemper virus. Viral Infections of Vertebrates 1: 133-159.

6. Bevilacwua PD, Paixao HH, Modena CM and Castro MCPS (2001). Urbanization of visceral leishmaniasis in Belo Horizonte, Brazil. Arquivo Brasileiro de Medicina Veterinariae Zootecnia 53: 1-8.

7. Chouinard L, Martineau D, Forget C and Girard C (1998). Use of polymerase chain reaction and histochemistry for detection of canine adenovirus type 1 in formalin fixed, paraffin embedded liver of dogs with chronic hepatitis or cirrhosis. Journal of Veterinary Diagnosis and Investigation 10: 320-325.

8. Cortes S, Rolão N, Ramada J and Campino L (2004). PCR as a rapid and sensitive tool in the diagnosis of human and canine leishmaniasis using Leishmania donovani s.l.-specific kinetoplastid primers. Transactions of the Royal Society of Tropical Medicine and Hygiene 98: 12-17.

9. Fouchier RAM, Bestebroer TM, Herfst S, Kemp LVD, Rimmelzwaan GF and Osterhaus ADME (2000). Detection of influenza A virus from different species by PCR amplification of conserved sequences in the matrix gene. Journal of clinical Microbiology 38: 4096-4101.

10. Frisk AL, Konig M, Moritz A and Baumgartnerm W (1999). Detection of canine distemper virus nucleoprotein RNA by reverse transcription-PCR using serum, whole blood and cerebrospinal fluid from dogs with distemper. Journal of Clinical Microbiology 37: 3634-3643.

11. Gomes AHS, Ferreira IMR, Lima MLSR, Cunha EA, Garcia AS, Araujo MFL and Pereira-Chioccola VL (2006). PCR identification of Leishmania in diagnosis and control of canine leishmaniasis. Veterinary Parasitology 144: 234-241.

12. Grech V, Mizzi J, Mangion M and Vella C (2000). Visceral leishmaniasis in Malta- an 18 year paediatric, population based study. Archives of Disease in Childhood 82: 381-385.

13. Greene CE (1990). Infectious Canine Hepatitis. Greene C E. (Ed.), Infectious Diseases of the Dog and Cat. WB Saunders, Philadelphia 242-251.

14. Keawcharoen J, Oraveerakul K, Kuiken T, Fouchier, RA, Amonsin A, Payungporn S, Noppornpanth S, Wattanodorn S, Theambooniers A, Tantilertcharoen R, Pattanarangsan R, Arya N, Ratanakorn P, Osterhaus DM and Poovorawan Y (2004). Avian influenza H5N1 in tigers and leopards. Emerging Infectious Diseases 10: 21892191.

15. Kelly RW (1993). The liver and biliary system. In: Pathology of Domestic Animals, edited by Jubb KVJ, Kennedy PC, Palmer N, $4^{\text {th }}$ edition. Academic Press, San Diego, CA: 364-366. 
Investigating infectious and zoonotic diseases of street dogs

16. Khan MAHNA, Khanm SS, Bashu J, Rima UK, Pervin M, Hossain MZ, Habib MA, Chowdhury MGA and Hossain MM (2012). Visceral leishmaniasis is endemic in Golden Jackals of Bangladesh Agricultural University Campus, a threat for expanding future zoonotic visceral leishmaniasis. Bangladesh Journal of Veterinary Medicine: 10: $97-105$.

17. Kim YH, Cho KW, Youn HY, Yoo HS and Han HR (2001). Detection of canine distemper virus (CDV) through one step RT-PCR combined with nested PCR. Journal of Veterinary Science 2: 59-63.

18. Labony SS, Begum N, Rima UK, Chowdhury MGA, Hossain MZ, Habib MA, Khan MAHNA (2014). Apply traditional and molecular protocols for the detection of carrier state of visceral leishmaniasis in black Bengal goat. IOSR Journal of Agriculture and Veterinary Science 7: 13-18.

19. Lipatov AS, Kwon YK, Sarmento LV, Lager KM, Spackman E, Suarez DL and Swayne DE (2008). Domestic pigs have low susceptibility to H5N1 highly pathogenic avian influenza viruses. PLoS Pathology 4: 43-49.

20. Luna LG (1968). Manual of Histologic Staining Methods of the Armed Forces Institute of Pathology. 3rd ed. McGraw-Hill, New York.

21. Mansur NS, Stauber LA and McCoy JR (1970). Leishmaniasis in the Sudan republic. Comparison and epidemiology implications of experimental canine infections with Sudanese, Mediterranean and Kenyan strains of Leishmania donovani. Journal of Parasitology 56: 468-472.

22. Messling V, Harder TC, Moennig V, Rautenberg P, Nolte I and Haas L (1999). Rapid and sensitive detection of immunoglobulin $\mathrm{M}(\mathrm{IgM})$ and $\operatorname{IgG}$ antibodies against canine distemper virus by a new recombinant nucleocapsid protein-based enzyme-linked immunosorbent assay. Journal of Clinical Microbiology 37: 1049-1056.

23. Mizak R, Dowden M and Davis PE (2002). Concurrent juvenile cellulites and metaphyseal osteopathy an atypical canine distemper virus syndrome. Australian Veterinary Practice 25: 62-67.

24. Noli C (1999). Canine leishmaniasis. Waltham Focus 9(2):16- 24.

25. Petersen CA (2009). Leishmaniasis, an Emerging Disease Found in Companion Animals in the United States. Tropical Companion Animal Medicine 24: 182-188.

26. Rezk HA (2000). Mites associated with stored dried-dates in Egypt and the role of Blattisocius keegani Fox as a biological control agent. Alexandria Journal of Agricultural Research 45: 179-191.

27. Saito TB, Alfieri AA, Wosiacki SR, Negrao FJ, Morais HAS and Alfieri AF (2006). Detection of canine distemper virus by reverse transcriptase-polymerase chain reaction in the urine of dogs with clinical signs of distemper encephalitis. Research of Veterinary Science 80: 116-119.

28. Shin YJ, Cho KO, Cho HS, Kang SK, Kim HJ, Kim YH, Park HS and Park NY (2004). Comparison of one-step RT-PCR and a nested PCR for the detection of canine distemper virus in clinical samples. Australian Veterinary Journal 82: 83-86.

29. Songserm T, Amonsin A, Jam-On R, Sae-Heng N, Pariyothorn N, Payungporn S, Theamboonlers A, Chutinimitkul S, Thanawongnuwech R and Poovorawan Y (2006). Fatal avian influenza A H5N1 in a dog. Emerging Infectious Diseases 12: 1744-1747.

30. Torres DF (2007). The role of dogs as reservoirs of Leishmania parasites, with emphasis on Leishmania infantum and Leishmania (Viannia) braziliensis. Veterinary Parasitology 149: 139-146.

31. Tryphonas L, Zawidzka Z, Bernard MA and Janzen EA (1977). Visceral Leishmaniasis in dog: clinical, Hematological and Pathological observations. Canadian Journal of comparative Medicine 41: 1-12.

32. Yousuf MA, Bashu J, Pervin M, Islam MT, Das PM and Khan MAHNA (2014). Indentifying diseases of Golden jackals of Bangladesh Agricultural University Campus, Mymensingh, Bangladesh. Bangladesh Journal of Veterinary Medicine 12: 217-224.

33. Zhu Q, Yang H, Chen W, Cao W, Zhong G, Jiao P, Deng G, Yu K, Yang C, Bu Z, Kawaoka Y and Chen H (2008). A naturally occurring deletion in its NS gene contributes to the attenuation of an H5N1 swine influenza virus in chickens. Journal Virology 82: 220-228. 